\title{
Rhodanese from Thiobacillus A2: Determination of Activity by Proton Nuclear Magnetic Resonance Spectroscopy
}

\author{
By MARVIN SILVER, * O. W. HOWARTH AND D. P. KELLY \\ Departments of Environmental Sciences and Molecular Sciences, University of \\ Warwick, Coventry $\mathrm{CV}_{4}{ }_{7 A L}$
}

(Received I2 April 1976)

SUMMARY

Rhodanese from Thiobacillus A2 was shown by proton nuclear magnetic resonance (NMR) spectroscopy to use dihydrolipoate or dihydrolipoamide as acceptor of the sulphane moiety of thiosulphate with the formation of $\alpha$-lipoate or lipoamide respectively. Correlation is shown between assays of the enzyme activity by NMR spectroscopy and by ultraviolet spectrophotometry.

\section{INTRODUCTION}

Rhodanese from Thiobacillus A2 uses dihydrolipoate or dihydrolipoamide as the acceptor of the sulphane moiety from thiosulphate with the production of $\alpha$-lipoate and lipoamide respectively; the persulphides of these compounds are transitory intermediates in this reaction (Silver \& Kelly, 1976). We now present confirmatory evidence obtained by proton nuclear magnetic resonance (NMR) spectroscopy for this reaction. This technique is particularly suitable for studying enzymic reactions which result in either major chemical change or deuteration of the substrate, as it detects changes in the chemical environment of all ${ }^{1} \mathrm{H}$ nuclei present in the reaction mixture.

\section{METHODS}

Rhodanese was isolated from Thiobacillus A2 as described previously (Silver \& Kelly, 1976). The enzyme for the NMR assay was precipitated by dialysis for $3 \mathrm{~h}$ against $1000 \mathrm{vols}$ saturated $\left(\mathrm{NH}_{4}\right)_{2} \mathrm{SO}_{4}\left(\mathrm{pH} 5^{\circ} \mathrm{O}\right)$, containing $\mathrm{IO}^{-3} \mathrm{M}-\mathrm{Na}_{2} \mathrm{~S}_{2} \mathrm{O}_{3}$, recovered by centrifuging at $13000 \mathrm{~g}$, and redissolved in a quantity of $\mathrm{D}_{2} \mathrm{O}$ equal to half the original volume. This resulted in the loss of 60 to $70 \%$ of the enzyme activity. $\mathrm{Na}_{2} \mathrm{~S}_{2} \mathrm{O}_{3}$ and dihydrolipoate were also dissolved in $\mathrm{D}_{2} \mathrm{O}$; dihydrolipoamide was dissolved in $50 \%(\mathrm{v} / \mathrm{v}) \mathrm{CD}_{3} \mathrm{OD}$ in $\mathrm{D}_{2} \mathrm{O}$. In all cases, solutions were adjusted to $\mathrm{pD} \mathbf{1 0} \cdot 2$ by the addition of solid $\mathrm{Na}_{2} \mathrm{CO}_{3}$.

The activity of rhodanese was determined colorimetrically by the formation of thiocyanate or spectrophotometrically by the formation of $\alpha$-lipoate or lipoamide as described previously (Silver \& Kelly, ${ }^{1976}$ ) with sufficient solid $\mathrm{Na}_{2} \mathrm{CO}_{3}$ added in place of Tris to adjust the pD to 10.2. The NMR reaction mixture contained: $5 \mu \mathrm{mol}$ dihydrolipoate or dihydrolipoamide; enzyme; and $5 \mu \mathrm{mol}$ thiosulphate, with which the reaction was routinely initiated. The volume of the reaction mixture was adjusted to $0.5 \mathrm{ml}$ by adding $\mathrm{D}_{2} \mathrm{O}$. A rhodanese preparation containing $24 \mu \mathrm{g}$ protein was used; this quantity of enzyme catalysed the formation of

* Permanent address: Département de Biochimie, Faculté des Sciences et de Génie, Université Laval, Québec GIK 7P4, Canada. 


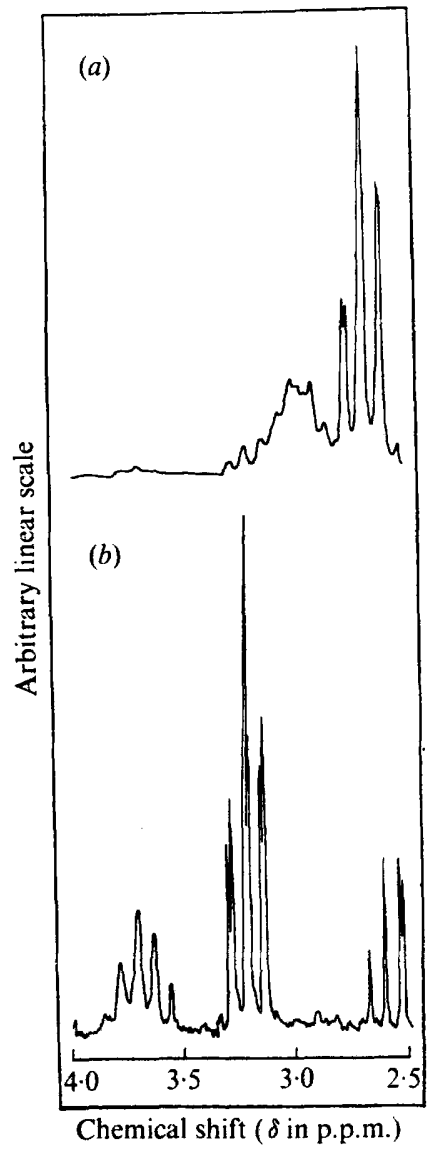

Fig. I

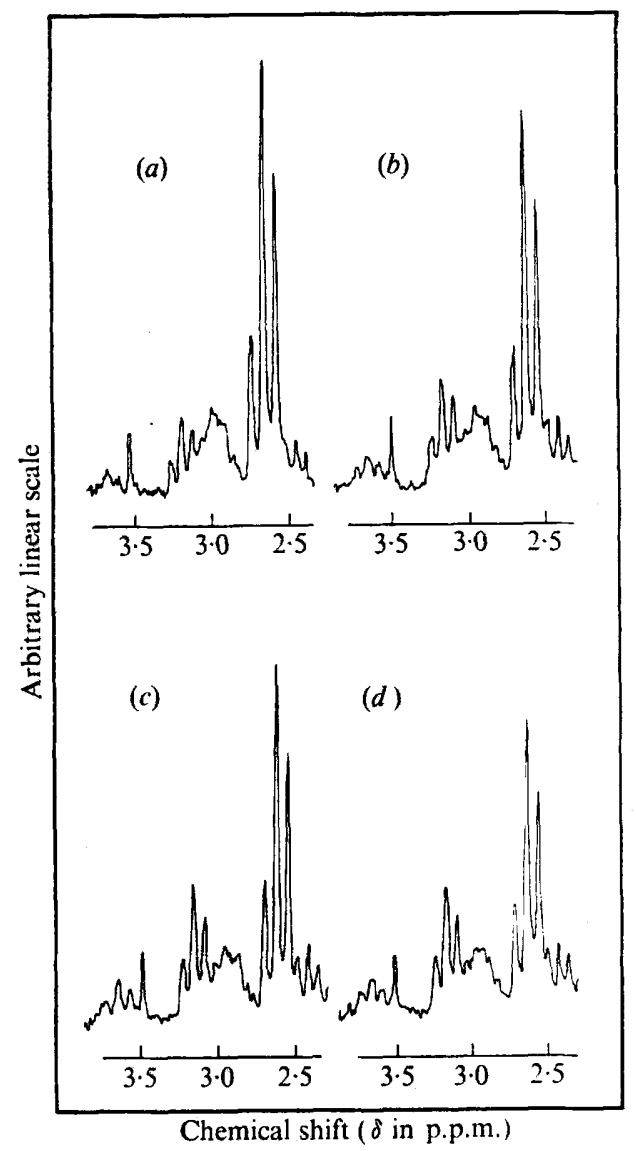

Fig. 2

Fig. I. Partial ${ }^{1} \mathrm{H}-\mathrm{NMR}$ spectra of $(a)$ dihydrolipoate and $(b) \alpha$-lipoate.

Fig. 2. Partial ${ }^{1} \mathrm{H}-\mathrm{NMR}$ spectra of rhodanese reaction mixture containing dihydrolipoate after incubation times (min) of $(a) 0,(b) 60,(c) 120$ and $(d)$ I 80.

$0.22 \mu \mathrm{mol}$ thiocyanate in Io min when assayed by the colorimetric method. The reaction was monitored by an automated observation of the NMR spectrum (Couch, Howarth \& Moore, 1975) every 15 or $20 \mathrm{~min}$ at $28^{\circ} \mathrm{C}$ in a Bruker spectrometer operating at $90 \mathrm{MHz}$. A delay of 4 to $8 \mathrm{~min}$ was experienced between the initiation of the reaction and the midpoint of the first spectrum recorded. For clarity, therefore, this first spectrum was taken arbitrarily as the initial point in calculation of the enzyme activity. Standard spectra of $\alpha$-lipoate and dihydrolipoate in $\mathrm{D}_{2} \mathrm{O}$, adjusted to $\mathrm{pD}$ Ir $\cdot 0$ with solid $\mathrm{Na}_{2} \mathrm{CO}_{3}$, and lipoamide and dihydrolipoamide in $\mathrm{CDCl}_{3}$, were recorded independently. Dihydrolipoate and dihydrolipoamide always contained 5 to $15 \% \alpha$-lipoate and lipoamide respectively as contaminants.

$\mathrm{D}_{2} \mathrm{O}, \mathrm{CD}_{3} \mathrm{OD}$ and $\mathrm{CDCl}_{3}$ (minimum isotope purity, 99 atom $\% \mathrm{D}$ ) were obtained from Merck, Sharp and Dohm Canada Ltd, Montreal. The sources of all other materials have been described previously (Silver \& Kelly, 1976). 


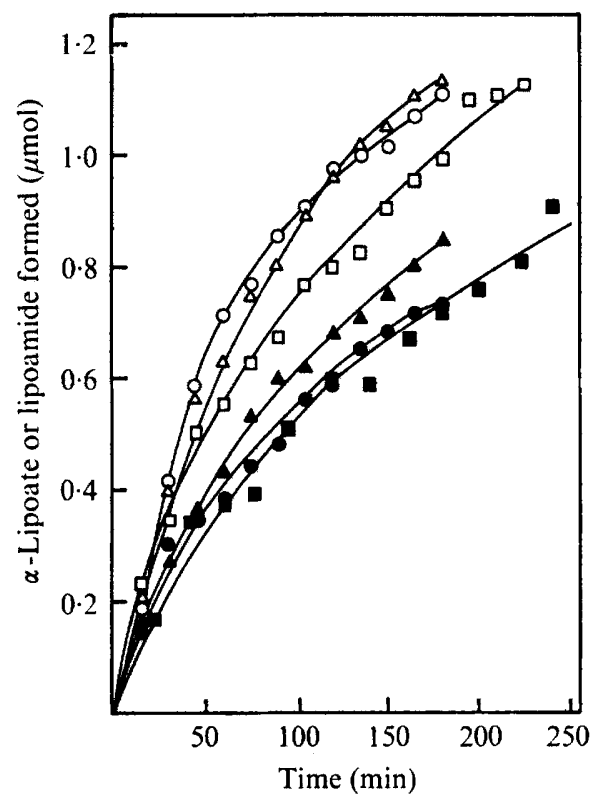

Fig. 3. Correlation of NMR assay and spectrophotometric assay of rhodanese in $\mathrm{D}_{2} \mathrm{O}$ or $\mathrm{H}_{2} \mathrm{O}$. NMR assay carried out in $\mathrm{D}_{2} \mathrm{O}$ with dihydrolipoate $(\square)$ or dihydrolipoamide ( $\square$ ) as substrate; spectrophotometric assay carried out in $\mathrm{H}_{2} \mathrm{O}$ with dihydrolipoate $(\Delta)$ or dihydrolipoamide $(\triangle)$, or in $\mathrm{D}_{2} \mathrm{O}$ with dihydrolipoate $(\mathrm{O})$ or dihydrolipoamide $(\mathrm{O})$.

\section{RESULTS AND DISCUSSION}

The multiplets centred at $\delta=2.68$ and 3.00 p.p.m. in the NMR spectrum of dihydrolipoate and at $\delta=3.22$ and 3.7I p.p.m. in the $\alpha$-lipoate spectrum (Fig. I) arose from the $\mathrm{CH}_{2}-\mathrm{S}$ and $\mathrm{CH}-\mathrm{S}$ protons respectively, which are well separated in chemical shift. The spectra of lipoamide and dihydrolipoamide were very similar in this region.

When NMR spectra were recorded at $20 \mathrm{~min}$ intervals during the reaction of rhodanese with dihydrolipoate, the formation of $\alpha$-lipoate could be seen (Fig. 2). The ratio of the heights of the $\alpha$-lipoate and dihydrolipoate multiplets equals the ratio of concentrations of the two species, as it is independent of any minor line-broadening in the spectrum, and is also independent of the observed $\mathrm{pD}$ decrease of between 0.4 and 0.5 units during the course of the reaction.

Correlation between the formation of $\alpha$-lipoate from dihydrolipoate and lipoamide from dihydrolipoamide when assayed by NMR spectroscopy or by u.v. spectrophotometry in either $\mathrm{D}_{2} \mathrm{O}$ or $\mathrm{H}_{2} \mathrm{O}$ (Fig. 3) shows that, as reported previously (Silver \& Kelly, 1976), the reaction was faster with dihydrolipoamide than with dihydrolipoate. In this case, the reaction measured by NMR spectroscopy was $38 \%$ faster with dihydrolipoamide than with dihydrolipoate. Similar differences were noted when the reactions were measured spectrophotometrically; little difference was noted in the rates of reaction in the presence of $\mathrm{D}_{2} \mathrm{O}$ or $\mathrm{H}_{2} \mathrm{O}$. The lack of a linear relationship of the enzyme activity with respect to time may be due either to the instability of the enzyme or to the aforementioned increase in acidity during the reaction. The former reason seems more probable, as the difference between the activity at

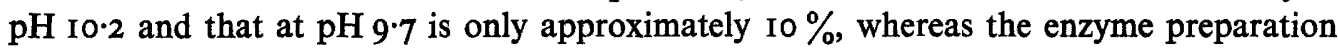
used in the previous study (Silver \& Kelly, 1976), which was more stable than that used in this study, lost $50 \%$ of its activity in $4 \mathrm{~h}$ at 0 to $4{ }^{\circ} \mathrm{C}$. 
We conclude that NMR spectroscopy is a further method for the study of rhodanese activity and has provided additional evidence for the production of $\alpha$-lipoate and lipoamide from the reaction of thiosulphate with dihydrolipoate and dihydrolipoamide catalysed by the Thiobacillus A2 enzyme.

This work was made possible by a travel fellowship from the National Research Council of Canada to M.S. We thank Jill Pothecary for technical assistance.

\section{REFERENCES}

Couch, D. A., Howarth, O. W. \& MOORE, P. (1975). Kinetic studies by stopped flow pulse Fourier transform nuclear magnetic resonance. Journal of Physics E: Scientific Instruments 8, 831-833.

SILVER, M. \& KELLY, D. P. (1976). Rhodanese from Thiobacillus A2: catalysis of reactions of thiosulphate with dihydrolipoate and dihydrolipoamide. Journal of General Microbiology 97, 277-284. 